\title{
English Language Teaching: Exploring Enhanced Employability through Soft Skills
}

\author{
Kabita Kumari Dash ${ }^{1}$, SwayamPrabha Satpathy ${ }^{2}$, Susanta Kumar Dash ${ }^{3}$ \\ ${ }^{1}$ Srusti Academy of Management \\ ${ }^{2}$ Associate Professor, SOA University. Email: dr.swayam.prava@gmail.com \\ 3OUAT
}

\begin{abstract}
250 under graduates and management students of SOA University of $1^{\text {st }}$ year, taken at random, were selected as subjects in this case study. 3 groups comprising of 30 students in each at random were given training on soft skill viz. grammar, vocabulary and speaking ability with 1 credit hour as extra class on Saturday during course curriculum Rest 160 students in same batch were taken as control. After one year of the of the final examination, means with incubation period of one year after the training period, it was found that $22(73.33 \%), 18(60.0 \%)$, and $28(93.33 \%)$ students belonging to Grammar, Vocabulary and Speaking ability group, respectively got a placement in the campus selection. The overall placement in the batch of students under trial was estimated as $105(42.0 \%)$ and the students without soft skill training was as low as 37(23.13\%), recorded in control group.
\end{abstract}

Key words: Communication, Employability, Language, Placement, Soft skill, Training

\section{Introduction}

With the changing educational scenario, adaptability in educational courses, requirement of qualified personnel, the competition for job acquisition and job sustainability is becoming more challenging and tough. To get a competitive edge, students are required to add values to their soft skills to show off their true potential. Soft skills are developed through regular orientation and trainings, self induced efforts, and strong inter personal communication. Many literature review advocate that hard skills contribute to only $15 \%$ of one's success while remaining $85 \%$ is made by soft skills. Most recruiters crave to hire, retain and promote persons who are trustworthy, innovative, self motivated, having good network and coordination, tremendous oratory skills, willingness to work and learn, and open to change processes with strong positive attitude.

With the beginning of economic liberalization and globalisation, the Indian market is becoming more aggressive and competitive and to fit in the global standards, the youth and students need to recognise their true potential through development of soft skills and show off their talent at various national and international forums. Realizing the gravity of communication issues, many educational institutes are now taking up several activities on priority basis for developing soft skills of their students to make them corporate ready. Technological advancements are paving path for knowledge economy and many service sectors have been introducing language learning, quality education and strengthening the training system for career growth and development of students. The emergence

(c) AesthetixMS 2020. This Open Access article is published under a Creative Commons Attribution Non-Commercial 4.0 International License (http://creativecommons.org/licenses/by-nc/4.o/), which permits non-commercial re-use, distribution, and reproduction in any medium, provided the original work is properly cited. For citation use the DOI. For commercial re-use, please contact editor@rupkatha.com. 
of knowledge economy dealing with productive improvements in many sectors such as engineering, management, information technology, health and hospitality sector in the form of problem solving ability, decision making, critical thinking, analytical skills, leadership development, innovative thinking, communication and personality development. Work place cultures have been changing and students are required to keep pace with this change management through continuous learning for a sustainable career growth and development. While hard skills deal with concept, academic skills, experience, subject knowledge and other quality indicators like techniques and principles for better performance ,soft skills deal with ,language learning, behavioural aspect, grooming etiquettes for better employability .

The present case study tries to analyse and understand various dynamics of soft skill problems of management and engineering students under SOA University leading to rejection during campus interviews, learning English as second language, the need and importance of soft skills for career development of students, and various strategies need to be taken up for language learning at graduate and postgraduate levels, The case study has put some valuable insights and come out with some valid recommendations on language learning for holistic development of students through introduction of soft skills so as to make them fit in the globally competitive environment.

\section{Review of literature}

Many corporate professionals believe that though graduates and management post graduates are technically qualified but due to lack of communication skills they could not crack any interviews. The students inability to communicate effectively during interviews and bigger forums are might be due to their stage fear and lack of confidence. (Nurita et al., 2007 in Zaharim et al., 2009).

Research says even Indian teachers are having strong mother tongue influence that's why students also lack proper communication skills which become a major hindrance in their professional career in a later stage. In the present context most of the engineering and management students are from general back ground who can never ever compete with the students of private English medium schools resulting in rejection and failure in most of the campus interviews. Students also show their reluctance to attend many campus interviews due to lack of communication skills. Many authors blame our current educational system which need to be reframed or redesigned keeping in view of soft skill development of students which can give them more employability option as desired by many corporate houses in India. The employers require skilled and competent human resource to meet the organisation goals. Nurita et al., 2007.

Kazamia (2012) and Norshima Zainal Shah (2008) stated that though engineers are technically sound and thorough in numbers, problems and constructions but they are very rarely taught on how to communicate it before a larger audience.They are efficient in theories but lack practical working knowledge .As they don't possess any rral field work experience sometimes they fail to perform better.

According to Mohammed(2017) effective communication should be the prime focus of engineering education but sometimes instructors face challenges while teaching humanities especially language and communication to engineering students. Therefore priority should be given more on individual and team presentations.

Rajprasit,K, Hemchua, S(2015) focussed on specially designed courses on English Language Communication as this is a global language and most desired communication skill as well .Effective Communication can enable engineers to work in an efficient manner. Moreover practical and realistic 
knowledge and skills can help both native and non native speakers for increased confidence and appropriate communication styles.

English is a global language and most widely used all over the world.It is the professional language for studying engineering in Nepal.English speaking skills can enhance more employability and it is easy to find a good job in Nepal if the student has excellent communication skills.Shrestha etal.,(2016)

To meet the growing demands of changing work place, employers rely mostly on efficient individuals having excellent presentation and communication skills (Hutchinson,et al., 1987). More over engineering and management students need to have updated knowledge, presentation skills, sales and negotiation skills to influence and motivate their clients .Efficent communicators can be productive employees also, who can contribute a lot towards organisations development.

Few years back fresh students of engineering and management were absorbed on the basis of their academic performance, technical knowledge during campus interviews but now however the situation have been changed. Corporate organisations are now looking for trained graduates on soft skills because of the globalisation and swift growth in the field information and communication technology. Bosses prefer to hire dynamic and young professionals having more confidence and excellent communication skills.So to meet this challenge,engineering and management courses need to be revised and redesigned keeping in view of the demands of this global competitive work environment . Murali and Rajaram (2015)

\section{Problem Assessment}

According to NWEA survey by Gallup, 2018 only $10 \%$ of Indians can understand and speak English in daily conversations with limited proficiency. However, people or students are sometimes seen good at listening, reading, writing but not in speaking English fluently and properly despite the focus and stress on English as a second language in the entire school and college curriculum. Another study showed $60 \%$ of employers felt a broad range of skills like inter personal skills, leadership ,team building, effective communication skills to be important for fresh engineering and management graduates to achieve long-term career success.

Ineffective curriculum design, absence of efficient teachers, lack of students' learning motivation, less knowledge on vocabulary, weak grammar, and fear of English are the strong reasons behind this language problem.

Most engineering graduates even management post graduates often face the challenges while learning English Communication in their curriculum .During campus and placement selection, their poor performance, lack of confidence and communication skills often lead to their failure and rejection.

- Excess Mother Tongue Influence(MTI)

- Stage fright and nervousness

- Lack of soft skills

- Lack of confidence and leadership traits

- Lack of motivation and the PUSH factor 
- Knowledge of grammar, vocabulary, syntax, pronunciation, and phonetics

- Untrained teachers.

- Limited learning environments.

- Less seriousness and interest to learn English

- Students become too dependent on the teacher.

\section{Objective}

The broad objective of preparation of this case study is to:

- Analyse and understand the language learning issues of students

- Importance of soft skills for better employment opportunity

- Suggest measures for a sustainable career growth through soft skill trainings

\section{Materials and Methods}

90 under graduates and management students of SOA University of $1^{\text {st }}$ year, taken at random were taken as subjects in this case study and further divided randomly into 3 groups containing 30 subjects in each group. All the 3 groups were given training on soft skill including Business Communication with 1 credit hour as extra class on Saturday. Training design for the first group was emphasised with grammar, second group on vocabulary and third group on speaking ability, phonetics and soft skill. Rest 160 students in same batch were taken as control. The soft skill training schedule was imparted for a period of 52 weeks. Then the result of the training was assessed on the basis of frequency of success in campus selection.

\section{Results and Discussion}

The results pertaining to the present study is presented in Table 1 . It is revealed that, after one year of the of the final examination, means with incubation period of one year after the training period, it was found that $22(73.33 \%), 18(60.0 \%)$, and $28(93.33 \%)$ students belonging to Grammer, Vocabulary and Speaking ability group, respectively got a placement in the campus selection. It is worthy to mention that the overall placement in the batch of students under trial was estimated as $105(42.0 \%)$ and the students without soft skill training was as low as $37(23.13 \%)$. Graphical presentations of the results with regard to enrolment vis-s-vis success and success vis-s-vis failure of students are presented in Fig. 1 and Fig 2, respectively.

Gross analysis of placement success in the present case reveals that the training on soft skills could prove to be beneficial in achieving success on campus placement, when compared with the contemporary students of same batch with an incubation period of one year after training. The present findings corroborate with that of Hutchinson et al. (1987) and Murali and Rajaram (2015).

Table 1. Impact of soft skill training on different groups of students

\begin{tabular}{|l|l|l|l|l|}
\hline Sl. No. & Group Name & $\begin{array}{l}\text { No. of enrolled } \\
\text { students }\end{array}$ & $\begin{array}{l}\text { No. of successful } \\
\text { students }\end{array}$ & of success \\
\hline 1 & Grammar & 30 & 22 & 73.33 \\
\hline
\end{tabular}


5 | English Language Teaching: Exploring Enhanced Employability through Soft Skills

\begin{tabular}{|l|l|l|l|l|}
\hline 2 & Vocabulary & 30 & 18 & 60.00 \\
\hline 3 & Speaking ability & 30 & 28 & 93.33 \\
\hline 4 & Control & 160 & 37 & 23.13 \\
\hline & Overall & 250 & 105 & 42.00 \\
\hline
\end{tabular}

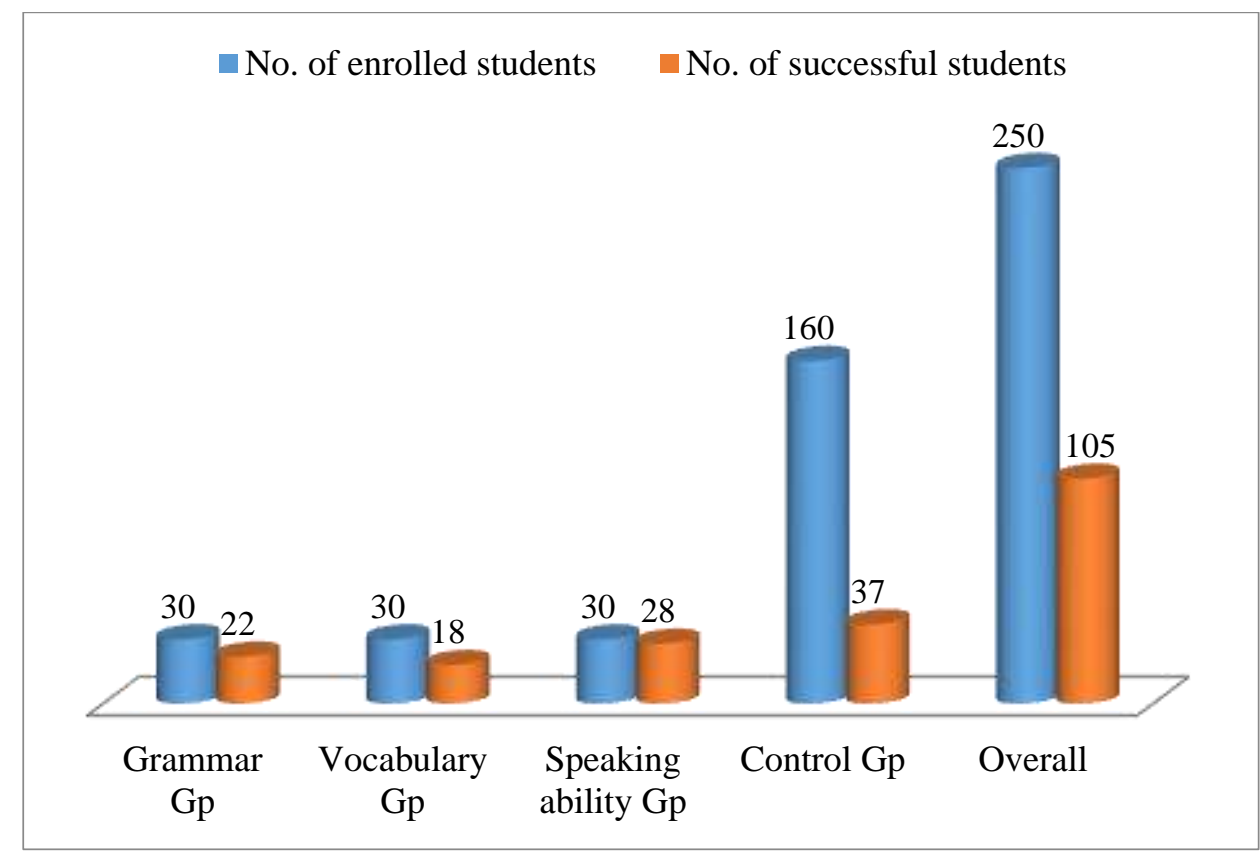

Fig 1. Number of enrolled vis-a-vis successful students over groups

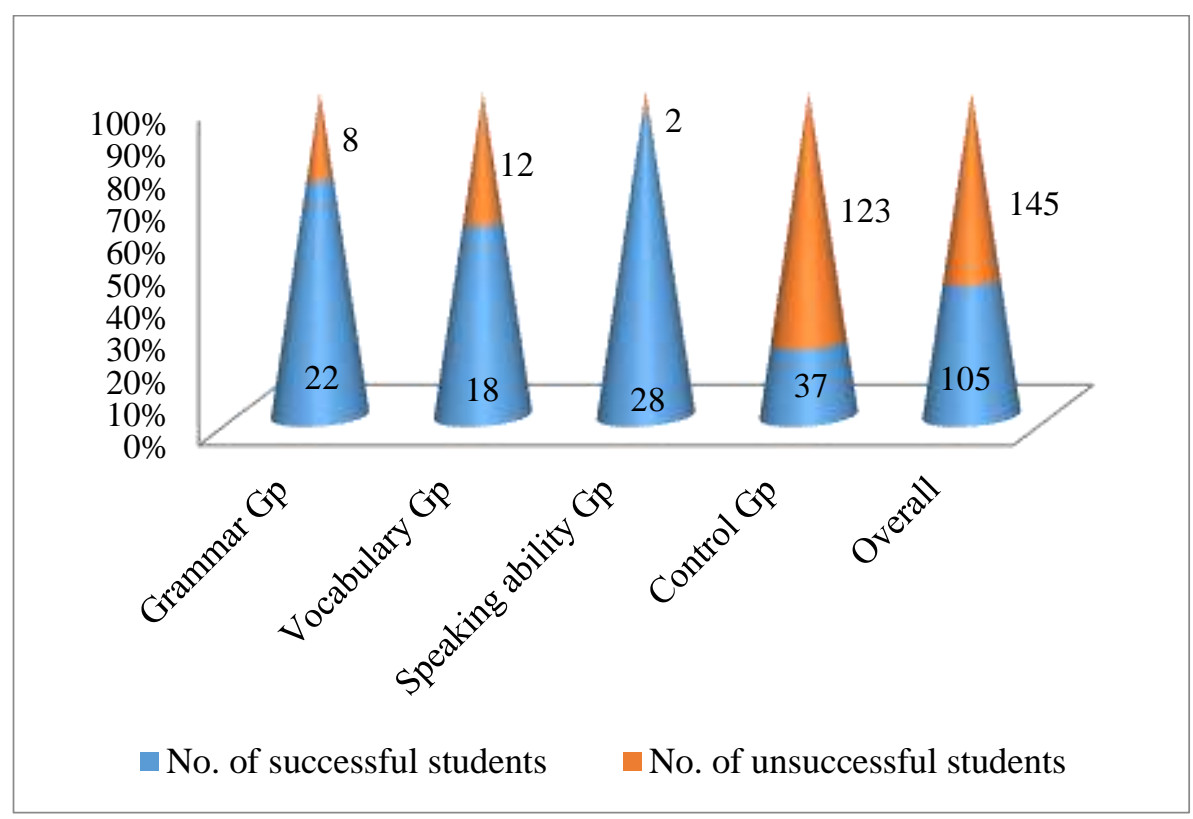


Fig 2. Comparison of successful vis-a-vis unsuccessful students over groups

\section{Limitations and Scope of study}

- Overall attendance of students under study during training period was $72 \%$,which should be increased to obtain better result.

- One year period of incubation was taken in present study, which may be given for two years to realize the effect.

- The soft skill training may be designed for $2^{\text {nd }}$ and $3^{\text {rd }}$ year to have more duration training.

- Different teachers may be engaged to impart such training to have diverse interaction of students during training.

- Mock interviews may be conducted to have better practical exposure and more success rate.

- More such studies with diverse group of students and with more numbers may be conducted to analyse the result with statistical significance.

\section{Suggestion and Recommendation}

- Defining skill set by the institution as per local, national and global requirements and standards.

- Curriculum design needs to integrate cognitive knowledge with soft skills and there should be an appropriate linkage between theory and practice for developing soft skills among students.

- Skilled faculties and trainers should understand the basic requirements of students and plan their teaching accordingly.

- Awareness and understanding on the importance of soft skills by the students in career development because better awareness lead to better knowledge and better job performance.

- Methodologies like lectures, demonstrations, role plays, case study analysis, group discussion, presentations, interview etiquettes with reasoning aptitude, regular field visits, conflict resolution techniques, practical examples, Just A Minute(JAM),extempore should be part of the curriculum to hone soft skills among students

- Industry experts should be invited for corporate talks and increased awareness of students

- Teachers should simulate real work place environment in the class room while teaching soft skills so that students practice corporate behaviour and other grooming etiquettes

\section{Conclusion}

To sum up, speaking of English language is important for better communication among engineering graduates and management post graduates especially in Universities and Corporate houses in India. Effective Communication is very much required to get a good job in our country. Employees have to strive hard and put their best efforts and work as per the directives of their employers so as to get a sustainable position in the organisation. Further, academic performance is not only the only factor which influence employers rather strong communication and personality traits are also of paramount importance. Employers also seek highly qualified and competitive individuals who can be fit in this globally competitive world, meet their expectations and take their organisations to achieve greater heights. 


\section{References:}

https://www.nwea.org/content/uploads/2018/o8/NWEA_Gallup-Study_August-2018.pdf Hutchinson, T., \& Waters, A. (1987). English for Specific Purposes: A Learner-Centered Approach. Cambridge: Cambridge University Press.

Kazamia,V(2012) Training engineers on communication skills in English, European Society for Engineering Education, 4oth Annual conference, Thessaloniki, Greece 23-26.

Mohammed,G (2017) Improving Communication and presentation skills in English for Engineering students for sustainability,International Journal of Quality in Education,vol 1(1),pp 1-12 Rajprasit,K.Hemchua,S(2015).The English Language \& Communication in the International Workplace:An examination of Thai Computer Engineering Professionals.The South East Asian Journal of English Language Studies, Vol 21(3)

Lee, F.T., and Tan, J.H., Project Management Skills Demand for Engineering Graduates in Malaysia,Jurutera (IEM Bulletin), June 2003, pp. 16-25.

Murali. S and Rajaram, Y. (2015), A Study on the Corporate Expectations from Engineering Graduates in India - Bangalore, IOSR Journal of Business and Management, Vol. 17(6):Ver. III, pp o1-o9.

Nurita etal. (2007) Study on Employability Skills of University Graduates. The Business

Wallpaper .Volume 2(1)..

Shah,N.Z. (2008). Are graduates to be blamed? Unemployment of Computer Science

Graduates in Malaysia. E-Journal of the American Association of Behavioural and Social Sciences, 18(Fall 2008).

Shrestha etal.(2016), Importance of English in Engineering for Professional Communication: A

Study in the Nepalese Context .Journal of the Institute of Engineering.12(1): 222-227

Dash,K(2019). English Language Teaching-A Paradigm shift towards employability through

soft skills-A case study on soft skill requirements of students under SOA

University.srustiacademy.org/UploadFile/SrustiDownload/Case\%2oStudy_Kabita\%2oDash.pdf 